\title{
Identifying Patient Characteristics Associated with High Schizophrenia-Related Direct Medical Costs in Community-Dwelling Patients
}

\author{
Pooja R. Desai, MS; Kenneth A. Lawson, PhD; Jamie C. Barner, PhD; and Karen L. Rascati, PhD
}

\begin{abstract}
BACKGROUND: Schizophrenia is a chronic, debilitating disease that affects approximately $1 \%$ of the U.S. population and has disproportionately high costs. Several factors, including age, gender, insurance status, and comorbid conditions, have been hypothesized to be associated with schizophreniarelated costs.
\end{abstract}

OBJECTIVE: To identify demographic and clinical characteristics of community-dwelling schizophrenia patients experiencing high schizophreniarelated direct medical costs.

METHODS: Community-dwelling patients with a diagnosis for schizophrenic disorder (ICD-9-CM code 295) and other nonorganic psychoses (ICD-9-CM code 298) were identified from the 2005-2008 Medical Expenditure Panel Survey (MEPS). Schizophrenia-related direct medical costs were calculated for (a) inpatient hospitalizations; (b) prescription medications; and (c) outpatient, office-based physician, emergency room, and home health care visits. Using Andersen's Behavorial Model of Health Services Use and the literature, factors that could potentially affect schizophrenia-related direct medical costs were identified. Based on the distribution of their mean annual costs, patients were classified into high- and low-cost groups. Logistic regression was used to determine the likelihood of high-cost group membership based on age, sex, race, insurance status, marital status, region of residence, family income as a percentage of poverty line, number of medical comorbidities, number of mental health-related comorbidities, patient-perceived general health status, patient-perceived mental health status, and year of inclusion in MEPS. In addition, a generalized linear model (GLM) regression (gamma distribution with a log-link function) was used to evaluate the relationships between the independent variables and total schizophrenia-related direct medical costs as a continuous variable. RESULTS: From the MEPS database, we identified 317 patients with schizophrenia who represented 2.75 million noninstitutionalized, community-dwelling schizophrenia patients in the United States between 2005 and 2008. The logistic regression procedure showed that older patients $(\mathrm{OR}=0.933,95 \% \mathrm{Cl}=0.902-0.966)$ and patients with a spouse ( $O R=0.150,95 \% \mathrm{Cl}=0.041-0.555)$ were less likely to be in the high-cost group, while those who reported having "poor" perceived general health status $(\mathrm{OR}=15.548,95 \% \mathrm{Cl}=1.278-189.127)$ were more likely to be in the high-cost group. The GLM regression procedure showed that younger patients (compared with older patients), African Americans (compared with Caucasions), patients with private insurance (compared with the uninsured), and those living in the northeastern United States (compared with those living in the southern United States) had higher schizophrenia-related direct medical costs.

CONCLUSION: Identification of factors associated with a high-cost population may help decision makers in managed care, government, and other organizations allocate resources more efficiently and health care providers manage patients more effectively through assignment of these patients to case managers and appropriate monitoring and treatment.

J Manag Care Pharm. 2013;19(6):468-77

Copyright $\odot 2013$, Academy of Managed Care Pharmacy. All rights reserved.

\section{What is already known about this subject}

- Schizophrenia is a debilitating disease that exerts a high financial burden on society.

- A study using the Medical Expenditure Panel Survey (McDonald 2005) has indicated that a small percentage of community-dwellers with schizophrenia are responsible for a disproportionate amount of associated costs.

- Factors such as early onset of disease, presence of comorbid conditions, hospitalizations, need for outpatient and emergency department visits, need for maintenance medications for long periods, and need for informal care have been hypothesized to be responsible for the high costs of schizophrenia

\section{What this study adds}

- This study used a combination of the Behavioral Model of Health Services Use and the literature to identify potential factors that might influence schizophrenia-related direct medical costs for community-dwelling individuals.

- The logistic regression procedure showed that after controlling for covariates, older patients and married patients were more likely to have lower costs, and those who reported having a "poor" perceived general health status were more likely to have higher costs.

- The generalized linear model regression procedure showed that younger patients (compared with older patients), African Americans (compared with Caucasions), patients with private insurance (compared with the uninsured), and those living in the northeastern United States (compared with those living in the southern United States) were associated with higher schizophreniarelated direct medical costs.

$O^{2}$ chizophrenia is a chronic, debilitating illness that is characterized by disturbances of language, perception, thinking, social activity, behavior, and decision-making skills. ${ }^{1}$ Several epidemiologic surveys have been conducted to estimate the prevalence of schizophrenia, such as the Epidemiologic Catchment Area study and the National Comorbidity Survey. These studies estimated the overall prevalence of schizophrenia in the United States to be between $0.3 \%$ and $1.6 \%$ of the population. ${ }^{2,3}$ 
Several studies also have been conducted to estimate the cost of schizophrenia in the United States. The costs associated with schizophrenia have shown a steady rise in the past few decades. Gunderson and Mosher's (1975) estimate for the total cost of schizophrenia in 1971 was between $\$ 11.6$ billion and $\$ 19.5$ billion, and the direct medical costs ranged from $\$ 2$ billion to $\$ 4$ billion. ${ }^{4}$ In 1985, Rice and Miller (1996) estimated the financial burden at $\$ 22.7$ billion of which $\$ 11.1$ billion was attributable to direct medical costs. ${ }^{5}$ Rice's $(1996)^{6}$ estimate updated to 1990 values was $\$ 32.5$ billion (direct medical cost $=\$ 17.3$ billion) and that of Wyatt et al. $(1995)^{7}$ for 1991 was $\$ 65.2$ billion, with direct medical costs accounting for about $\$ 19$ billion. The most recent estimate by Wu et al. (2005) for 2002 costs was $\$ 62.7$ billion (direct medical costs $=\$ 22.7$ billion). ${ }^{8}$ Another study conducted in 2001-2002 by McDonald et al. (2005) estimated the schizophrenia-associated direct medical costs at $\$ 2.13$ billion. ${ }^{9}$ This wide range of estimates is probably due to differences in study time periods, costs included, measurement of costs, and patient populations.

Conwell and Cohen's report (2005), based on the 2002 Medical Expenditure Panel Survey (MEPS), a nationally representative annual survey of noninstitutionalized U.S. residents, indicated that $5 \%$ of the American population was responsible for $49 \%$ of the medical expenditure for all conditions, while half the population was responsible for only $3 \%$ of the total expenditures. ${ }^{10}$ McDonald et al.'s estimate for the direct cost of schizophrenia showed a similar pattern, where about $0.36 \%$ $(\mathrm{N}=571,000)$ of community-dwelling patients with schizophrenia and related psychoses were responsible for $\$ 2.13$ billion in direct medical costs during 2001-2002. ${ }^{9}$ Investigators such as Terkelsen and Menikoff (1995) have hypothesized that several factors, such as early onset of disease, presence of comorbid conditions, hospitalizations, need for outpatient and emergency room visits, need for maintenance medications for prolonged periods, and constant requirement of informal support and supervision, are responsible for the high cost of schizophrenia. ${ }^{11}$ Identifying characteristics of high-cost patients may be useful for health care providers and managed health care organizations in designing interventions for schizophrenia treatment that target this high-risk population.

Anderson's Behavorial Model of Health Services Use provides a theoretical framework to understand factors influencing use of health care services. Utilization of health services is associated with costs because higher utilization of health care services leads to higher costs. Andersen's model includes 3 sets of factors: Predisposing factors include sociodemographic characteristics; enabling factors include those that facilitate or impede the use of health care services; and need factors include indicators of health status. We used Andersen's model and the literature to identify factors that could potentially be associated with high schizophrenia-related direct medical costs. ${ }^{12,13}$ Several studies have shown that age, gender, insurance status, and presence of comorbid conditions are associated with schizophrenia-related costs. ${ }^{14-17}$ The prevalence of schizophrenia varies by age, gender, race, insurance status, family income as a percentage of poverty line, and marital status., ${ }^{3,18}$ Thus, we also expected the costs to vary by these factors. In addition, we also examined how patient-perceived general health status and mental health status were associated with costs.

Community-dwellers are an important population to consider because in recent years there has been movement towards de-institutionalization due to the Omnibus Budget Reconciliation Act (OBRA) of $1987 . .^{19}$ Thus, the objective of this study was to determine if significant associations exist between patient demographic and clinical factors and "high" schizophrenia-related direct medical costs among communitydwelling patients using the MEPS database.

\section{Methods}

The retrospective database analysis used 2005-2008 MEPS data. It was approved by the Institutional Review Board of the University of Texas at Austin. MEPS was first conducted in 1996 and is administered annually for civilian noninstitutionalized Americans. ${ }^{20}$ It collects information from individuals and families, their medical providers, and employers. An overlapping panel design is used for this purpose. ${ }^{21}$ Each panel collects data over a two-and one-half-year period using 5 rounds of interviews, which yields 2 full years of data. The information collected includes the type, usage frequency, cost, and method of payment for various medical services; detailed insurance information; access to care; satisfaction with care; employment information; and demographic characteristics. MEPS has 3 components: the household component (HC); the medical provider component (MPC); and the insurance component (IC). Information in the HC is collected by self-report, and the MPC is used to validate and supplement information collected in the HC. For the purposes of this study, only the HC information was used. ${ }^{21}$ The full-year consolidated data file, medical conditions data file, and the event data files for inpatient hospitalizations, outpatient visits, office-based physician visits, emergency room visits, home health care visits, and prescription medications were merged prior to conducting analyses. Demographic information and expenditure data were utilized for the analyses. Data files from 2005-2008 were combined to obtain the final analytical dataset. Pooling data over several years increases the precision of estimates for the subpopulation of patients with schizophrenia.

Patients with a diagnosis of schizophrenic disorder (International Classification of Diseases, Ninth Revision, Clinical Modification [ICD-9-CM] code 295) and other nonorganic psychosis (ICD-9-CM code 298) were identified from the MEPS data. Patients of all ages, genders, and ethnicities were included in the study. Schizophrenia-related direct medical costs were calculated and summed for the following service utilization categories: inpatient hospitalizations, outpatient 
visits, office-based physician visits, emergency room visits, home health care visits, and prescription medications. Outpatient visits included visits to a unit of a hospital or facility connected to a hospital providing health and medical services to individuals who receive services from the hospital but do not require overnight hospitalization. ${ }^{20}$ Office-based physician visits included visits to doctors or group practice offices, medical clinics, managed care plans or health maintenance organization centers, neighborhood/family/community health centers, surgical centers, rural health clinics, company clinics, school clinics, walk-in urgent centers, Veterans Administration (VA) facilities, or laboratory/x-ray facilities. Only events associated with an ICD-9-CM code of 295 and 298 were included to ensure that only schizophrenia-related costs were captured in the analysis. The schizophrenia-related direct costs included MEPS-reported amounts paid by the following sources: patient and/or family, Medicare, Medicaid, VA, TRICARE, other federal sources, local and state government sources, worker's compensation, private insurance, and other sources of insurance. A societal perspective was used for the study. Determinants of high costs were identified based on their relationships with direct medical costs. The cost variable was dichotomized into high-cost (expenditures $\geq \$ 16,000$ ) and low-cost (expenditures $<\$ 16,000)$ groups based on a natural break in the distribution of costs, while ensuring that there were sufficient patients in each group. Demographic and clinical characteristics were compared between the high- and low-cost groups using t-tests (for continuous variables) and Rao-Scott chi-square tests (for categorical variables). Logistic regression was carried out using the dichotomized cost variable as the dependent variable and age, sex, race, marital status, insurance status, family income as a percentage of the federal poverty level, region of residence, patient-perceived general health status, patient-perceived mental health status, number of medical comorbidities, and the number of mental health-related comorbidities as independent variables. Medical comorbidities included hepatic disorder, hyperlipidemia, hypertension, diabetes, obesity, asthma, and human immunodeficiency virus infection/acquired immunodeficiency syndrome. Mental health-related comorbidities included psychiatric diagnoses, anxiety, and substance and alcohol use disorders.

Because of the limited sample size, the $95 \%$ confidence intervals $(\mathrm{CI})$ of the odds ratios (OR) were very wide. Therefore, a second analytical approach was undertaken using a generalized linear model (GLM) analysis to conduct a regression procedure employing a gamma distribution and a log-link function. Total schizophrenia-related cost (as a continuous variable) was used as the dependent variable, and age, sex, race, marital status, insurance status, region of residence, family income as a percentage of the federal poverty level, patient-perceived general health status, patient-perceived mental health status, number of medical comorbidities, and number of mental health-related comorbidities were used as the independent

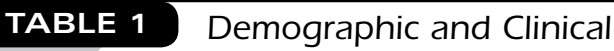 Characteristics of the Schizophrenia Population}

\begin{tabular}{|c|c|c|c|}
\hline $\begin{array}{l}\text { Demographic/ } \\
\text { Clinical } \\
\text { Characteristics }\end{array}$ & Categories & Weighted N & Percentage \\
\hline Age [mean (SE)] & & $3,031,572$ & $43.1(1.4)$ \\
\hline \multirow[t]{2}{*}{ Sex } & Male & $1,674,993$ & 55.2 \\
\hline & Female & $1,356,579$ & 44.8 \\
\hline \multirow[t]{6}{*}{ Race } & Caucasian & $2,152,830$ & 71.0 \\
\hline & African American & 719,947 & 23.8 \\
\hline & $\begin{array}{l}\text { American Indian/ } \\
\text { Alaska Native }\end{array}$ & 12,467 & 0.4 \\
\hline & Asian & 12,100 & 0.4 \\
\hline & $\begin{array}{l}\text { Native Hawaiian/ } \\
\text { Pacific Islander }\end{array}$ & 1,869 & 0.1 \\
\hline & Multiple races reported & 132,359 & 4.4 \\
\hline \multirow[t]{3}{*}{ Insurance status } & Any private & 617,788 & 20.4 \\
\hline & Public only & $2,192,729$ & 72.3 \\
\hline & No insurance & 221,055 & 7.3 \\
\hline \multirow[t]{6}{*}{ Marital status } & Married & 418,588 & 13.8 \\
\hline & Widowed & 253,304 & 8.4 \\
\hline & Divorced & 589,250 & 19.4 \\
\hline & Separated & 70,639 & 2.3 \\
\hline & Never married & $1,607,544$ & 53.0 \\
\hline & $\begin{array}{l}\text { Inapplicable-below } \\
16 \text { years }\end{array}$ & 92,246 & 3.0 \\
\hline \multirow[t]{5}{*}{ Region of residence } & Northeast & 676,684 & 22.3 \\
\hline & Midwest & 600,036 & 19.8 \\
\hline & South & $1,028,532$ & 33.9 \\
\hline & West & 591,077 & 19.5 \\
\hline & Not reported & 135,243 & 4.5 \\
\hline \multirow{5}{*}{$\begin{array}{l}\text { Family income as } \\
\text { a percentage of } \\
\text { the federal poverty } \\
\text { levela }\end{array}$} & Poor/negative & $1,031,972$ & 34.0 \\
\hline & Poor & 380,824 & 12.6 \\
\hline & Low income & 554,599 & 18.3 \\
\hline & Mid income & 666,674 & 22.0 \\
\hline & High income & 397,503 & 13.1 \\
\hline \multirow{5}{*}{$\begin{array}{l}\text { Patient-perceived } \\
\text { health status }\end{array}$} & Excellent & 181,964 & 6.0 \\
\hline & Very good & 576,658 & 19.1 \\
\hline & Good & $1,007,110$ & 33.3 \\
\hline & Fair & 944,782 & 31.2 \\
\hline & Poor & 314,905 & 10.4 \\
\hline \multirow{5}{*}{$\begin{array}{l}\text { Patient-perceived } \\
\text { mental health } \\
\text { status }\end{array}$} & Excellent & 84,822 & 2.8 \\
\hline & Very good & 336,678 & 11.1 \\
\hline & Good & 796,265 & 26.3 \\
\hline & Fair & $1,249,139$ & 41.3 \\
\hline & Poor & 558,515 & 18.5 \\
\hline \multicolumn{2}{|c|}{ Number of medical comorbidities [mean (SE)] } & $3,031,572$ & $0.85(0.07)$ \\
\hline \multicolumn{2}{|c|}{$\begin{array}{l}\text { Number of mental health-related comorbidities } \\
\text { [mean (SE)] }\end{array}$} & $3,031,572$ & $1.11(0.11)$ \\
\hline \multirow[t]{4}{*}{ Year } & 2005 & 718,835 & 23.7 \\
\hline & 2006 & 611,240 & 20.2 \\
\hline & 2007 & 893,953 & 29.5 \\
\hline & 2008 & 807,543 & 26.6 \\
\hline
\end{tabular}

a Family income as a percentage of the federal poverty level (FPL) was defined as follows: Poor/negative: less than 1.00 times the FPL; Poor: 1.01 to 1.24 times the FPL; Low income: 1.25 to 1.99 times the FPL; Middle income: 2.00 to 3.99 times the FPL; High income: 4.0 or more times the FPL.

$S E=$ standard error. 


\section{FIGURE 1 Flowchart for Patient Inclusion Criteria}

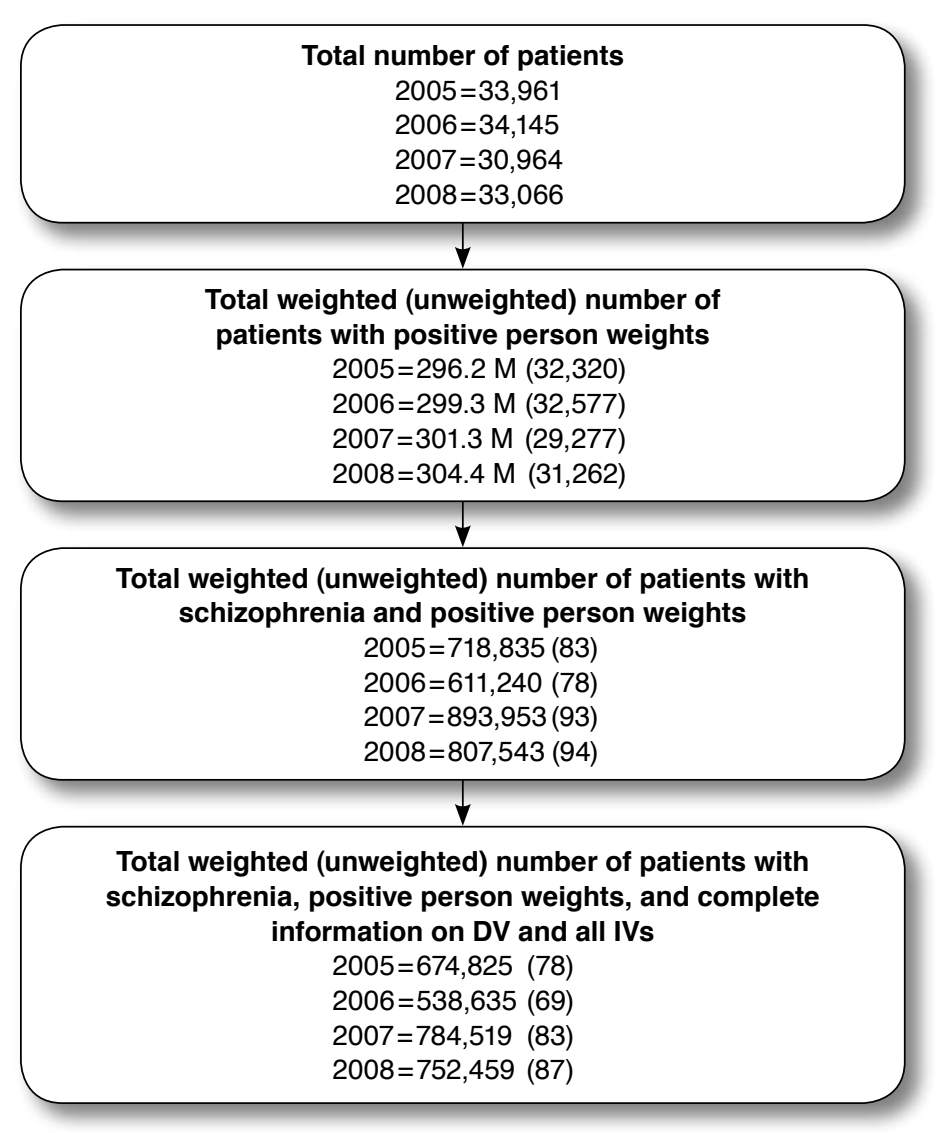

$\mathrm{DV}=$ dependent variable; $I V=$ independent variable; $M=$ million.

variables. A modified Park test was used to determine the appropriate model for the analysis. ${ }^{22}$ This test was conducted by regressing the natural log of the squared residual on the natural log of the predicted value of the dependent variable..$^{23}$

All analyses were conducted using SAS version 9.2 (SAS Institute Inc., Cary, NC) and Stata version 12 (Stata Corp. LP, College Station, TX). The "survey" procedure of SAS and the "svy" procedure of Stata were used to calculate accurate point estimates and their associated standard errors for the civilian noninstitutionalized population incorporating the MEPS survey weights and accounting for the complex, multistage sampling design of MEPS. The participating individuals in MEPS represent only a fraction of the overall population intended to be reflected by the survey. In order to represent the overall population, responses of the surveyed individuals must be weighted by the proportion of the population they represent. Thus, the person weights provided in the MEPS dataset were used to derive national estimates; these weights take into account poststratification and nonresponse adjustments.

\section{FIGURE 2 Distribution of Annual Schizophrenia-} Related Direct Medical Costs

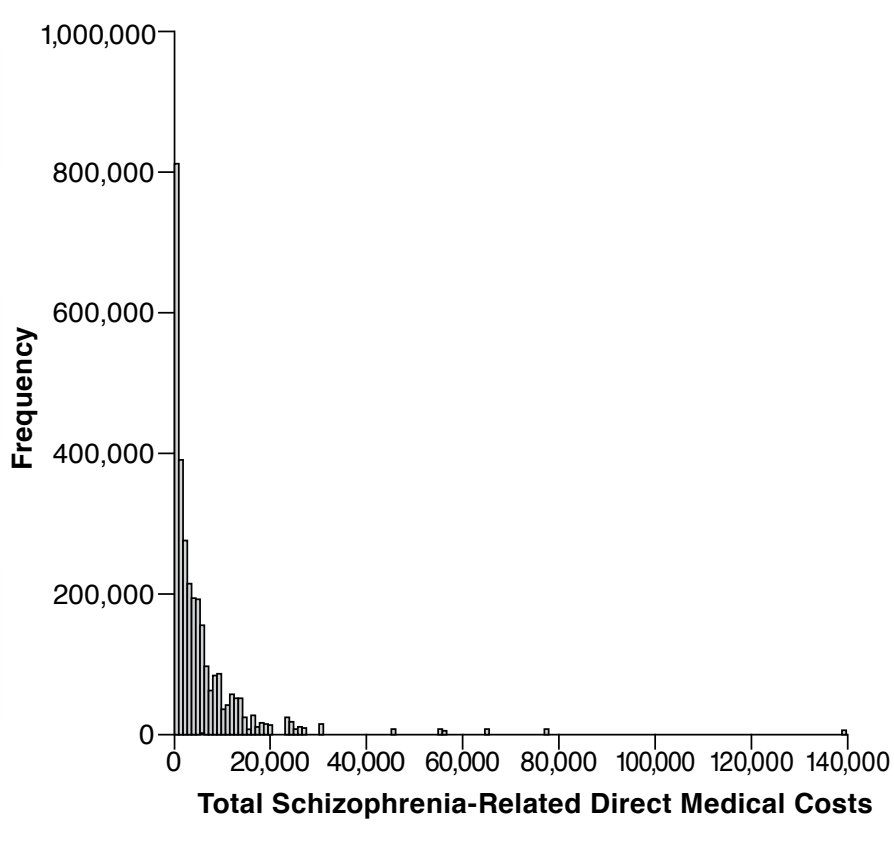

\section{Results}

We identified 348 patients with a diagnosis of schizophrenia in the 2005-2008 MEPS data, which represents 3.03 million noninstitutionalized U.S. residents. Table 1 provides the demographic and clinical characteristics of the schizophrenia population included in this study.

Of the 3.03 million patients with schizophrenia in MEPS, 2.86 million (unweighted frequency $=327$ ) reported having schizophrenia-related direct medical costs. Of those, 2.75 million (unweighted frequency $=317$ ) patients had complete information on all the variables required for the regression procedure, so they were included in subsequent analyses (Figure 1 ). The average annual cost per patient was $\$ 5,402$ (standard error $[\mathrm{SE}]=\$ 580$ ). Figure 2 shows the frequency distribution of the weighted schizophrenia-related direct medical costs for the patients. Based on the distribution, $\$ 16,000$ was selected as the cutoff point for the high-cost group for the logistic regression procedure. For the regression procedure, some of the categories for race, marital status, family income as a percentage of the federal poverty level, patient-perceived general health status, and patient-perceived mental health status were combined in order to ensure a sufficient sample size in each category. Patients who were unmarried (separated, divorced, widowed, or never married) were grouped together as they would likely have less family support compared with those who were married or under age 16 (and likely to be living with their parents). The sample size for the group of patients under age 16 was too small to make it a separate category. 


\section{TABLE 2 Chi-square Analysis of Demographic and Clinical Characteristics by High- and Low-Cost Goups}

\begin{tabular}{|c|c|c|c|c|c|c|c|}
\hline \multirow{2}{*}{$\begin{array}{l}\text { Demographic/Clinical } \\
\text { Variables }\end{array}$} & \multirow[b]{2}{*}{ Categories } & \multicolumn{2}{|c|}{ Low-Cost Group } & \multicolumn{2}{|c|}{ High-Cost Group } & \multirow[t]{2}{*}{\begin{tabular}{|c} 
Rao-Scott \\
Chi-square \\
Statistic \\
\end{tabular}} & \multirow[t]{2}{*}{$P$ Value } \\
\hline & & Weighted $\mathrm{N}$ & Percentage & Weighted N & Percentage & & \\
\hline \multirow[t]{2}{*}{ Gender } & Male & $1,411,669$ & 55.3 & 115,560 & 58.4 & 0.0651 & 0.799 \\
\hline & Female & $1,140,966$ & 44.7 & 82,243 & 41.6 & & \\
\hline \multirow[t]{3}{*}{ Race } & African American & 597,416 & 23.4 & 79,017 & 40.0 & 3.5244 & 0.172 \\
\hline & Caucasian & $1,838,278$ & 72.0 & 105,750 & 53.5 & & \\
\hline & Other ${ }^{\mathrm{a}}$ & 116,941 & 4.6 & 13,036 & 6.6 & & \\
\hline \multirow[t]{2}{*}{ Marital status } & Has spouse or is less than 16 years of age ${ }^{b}$ & 444,430 & 17.4 & 10,858 & 5.5 & 3.5561 & 0.059 \\
\hline & No spouse ${ }^{\mathrm{C}}$ & $2,108,205$ & 82.6 & 186,945 & 94.9 & & \\
\hline \multirow{3}{*}{$\begin{array}{l}\text { Insurance } \\
\text { coverage }\end{array}$} & Private insurance & 529,186 & 20.7 & 24,514 & 12.4 & 0.9641 & 0.618 \\
\hline & Public insurance & $1,855,088$ & 72.7 & 155,768 & 78.8 & & \\
\hline & No insurance & 168,361 & 6.6 & 17,520 & 8.9 & & \\
\hline \multirow[t]{4}{*}{ Region } & Northeast & 602,839 & 23.6 & 53,972 & 27.3 & 1.6792 & 0.642 \\
\hline & Midwest & 521,040 & 20.4 & 44,189 & 22.3 & & \\
\hline & South & 961,127 & 37.7 & 45,781 & 23.1 & & \\
\hline & West & 467,628 & 18.3 & 53,861 & 27.2 & & \\
\hline \multirow{2}{*}{$\begin{array}{l}\text { Family income as a percentage } \\
\text { of federal poverty level }\end{array}$} & Low incomed & $1,621,586$ & 63.5 & 146,081 & 73.9 & 0.5785 & 0.447 \\
\hline & High income $e^{e}$ & 931,049 & 36.5 & 51,722 & 26.2 & & \\
\hline \multirow{3}{*}{$\begin{array}{l}\text { Patient-perceived general } \\
\text { health status }\end{array}$} & Excellent ${ }^{\mathrm{f}}$ & 657,223 & 25.8 & 39,304 & 19.9 & 1.4116 & 0.494 \\
\hline & Goodg & $1,664,453$ & 65.2 & 124,945 & 63.2 & & \\
\hline & Poor & 230,959 & 9.1 & 33,553 & 17.0 & & \\
\hline \multirow{3}{*}{$\begin{array}{l}\text { Patient-perceived mental } \\
\text { health status }\end{array}$} & Excellent ${ }^{\mathrm{f}}$ & 338,073 & 13.2 & 28,859 & 14.6 & 0.4367 & 0.804 \\
\hline & Goodg & $1,741,993$ & 68.2 & 144,514 & 73.1 & & \\
\hline & Poor & 472,569 & 18.5 & 24,430 & 12.4 & & \\
\hline \multirow[t]{4}{*}{ Year } & 2005 & 612,120 & 24.0 & 62,705 & 31.7 & 1.4189 & 0.710 \\
\hline & 2006 & 498,007 & 19.5 & 40,628 & 20.5 & & \\
\hline & 2007 & 751,972 & 29.5 & 32,548 & 16.5 & & \\
\hline & 2008 & 690,537 & 27.1 & 61,923 & 31.3 & & \\
\hline \multicolumn{8}{|c|}{$\begin{array}{l}\text { "American Indian/Alaskan Native, Asian, Native Hawaiian/Paci } \\
{ }^{b} \text { Married and less than aged } 16 \text { years collapsed into "Has spouse } \\
\text { "Widowed, divorced, separated, and never married collapsed into } \\
{ }^{d} \text { Poor/negative, poor, low income collapsed into "Low income." } \\
\text { "Middle income and high income collapsed into "High income." } \\
\text { fExcellent and very good collapsed into "Excellent." } \\
\text { gGood and fair collapsed into "Good." }\end{array}$} \\
\hline
\end{tabular}

There were 197,803 patients (unweighted frequency=21) in the high-cost group and 2.55 million patients (unweighted frequency $=296$ ) in the low-cost group. The mean cost per patient-year was $\$ 3,656(\mathrm{SE}=\$ 283)$ for the low-cost group and $\$ 27,944$ (SE $=\$ 4,639)$ for the high-cost group. Descriptive statistics and results of statistical comparisons for the categorical demographic and clinical characteristics by the high- and low-cost groups are reported in Table 2, and those for the continuous demographic and clinical characteristics are provided in Table 3. Table 4 provides the mean costs and the proportions of costs for the different service utilization categories for the low- and high-cost groups. Inpatient hospitalizations (low-cost $=10.1 \%$, high-cost $=28.5 \%$, office-based physician visits (low-cost $=26.8 \%$, high-cost $=24.5 \%$ ), and prescription medications (low-cost $=52.3 \%$, high-cost $=22.7 \%$ ) accounted for a large proportion of the expenditures in both groups.
Rao-Scott chi-square tests and t-tests demonstrated that there were no statistically significant differences between the 2 groups with respect to demographic or clinical characteristics except for age. Patients in the low-cost group were older than those in the high-cost group (43.7 years vs. 34.6 years; $P=0.0021$ ).

A logistic regression procedure was carried out with high- $(\geq \$ 16,000)$ and low- $(<\$ 16,000)$ cost categories (based on direct costs) as the dependent variable and age, gender, race, marital status, insurance coverage, family income as a percentage of the federal poverty level, region of residence, patient-perceived general health status, patient-perceived mental health status, number of medical comorbidities, and the number of mental health-related comorbidities as the independent variables. Table 5 provides the regression coefficients, 


\section{Identifying Patient Characteristics Associated with High Schizophrenia-Related Direct Medical Costs in Community-Dwelling Patients}

\section{TABLE 3 T-test Analysis of Demographic and Clinical Characteristics by High- and Low-Cost Groups}

\begin{tabular}{|c|c|c|c|c|c|c|}
\hline \multirow{2}{*}{$\begin{array}{l}\text { Demographic/Clinical } \\
\text { Variables }\end{array}$} & \multicolumn{2}{|c|}{$\begin{array}{l}\text { Low-Cost } \\
\text { Group }\end{array}$} & \multicolumn{2}{|c|}{$\begin{array}{l}\text { High-Cost } \\
\text { Group }\end{array}$} & \multirow{2}{*}{$\begin{array}{c}\mathrm{T}- \\
\text { statistic }\end{array}$} & \multirow{2}{*}{$\begin{array}{c}P \\
\text { Value }\end{array}$} \\
\hline & Mean & SE & Mean & $\mathrm{SE}$ & & \\
\hline Age $^{\mathrm{a}}$ & 43.70 & 1.40 & 34.60 & 2.90 & -3.09 & 0.002 \\
\hline $\begin{array}{l}\text { Number of clinical } \\
\text { comorbidities }\end{array}$ & 0.88 & 0.08 & 0.71 & 0.22 & -0.78 & 0.434 \\
\hline $\begin{array}{l}\text { Number of mental } \\
\text { health-related } \\
\text { comorbidities }\end{array}$ & 1.18 & 0.11 & 0.98 & 0.39 & -0.53 & 0.598 \\
\hline $\begin{array}{l}a P<0.05 . \\
S E=\text { standard error. }\end{array}$ & & & & & & \\
\hline
\end{tabular}

\section{TABLE 4 Mean Costs Per Patient by Health Care Utilization Category for the Low- and High-Cost Groups}

\begin{tabular}{l|c|c}
\hline & $\begin{array}{c}\text { Low-Cost Mean } \\
\text { Cost Category }\end{array}$ & $\begin{array}{c}\text { High-Cost Mean } \\
(\mathrm{SE})[\%]\end{array}$ \\
\hline Inpatient hospitalizations & $\$ 367.76(\$ 104.62)$ & $\$ 7,962.18(\$ 3,133.80)$ \\
& {$[10.1]$} & {$[28.5]$} \\
\hline Outpatient visits & $\$ 93.98(\$ 31.24)$ & $\$ 635.39(\$ 574.80)$ \\
& {$[2.6]$} & {$[2.3]$} \\
\hline Office-based physician visits & $\$ 979.66(\$ 154.65)$ & $\$ 6,836.61(\$ 1,799.28)$ \\
& {$[26.8]$} & {$[24.5]$} \\
\hline Emergency room visits & $\$ 17.93(\$ 7.23)$ & $\$ 237.14(\$ 166.07)$ \\
& {$[0.5]$} & {$[0.8]$} \\
\hline Home health care visits & $\$ 280.40(\$ 111.49)$ & $\$ 5,933.25(\$ 3,613.74)$ \\
& {$[7.7]$} & {$[21.2]$} \\
\hline Prescription medications & $\$ 1,915.85(\$ 175.84)$ & $\$ 6,338.95(\$ 1,449.93)$ \\
& {$[52.4]$} & {$[22.7]$} \\
\hline Total & $\$ 3,656(\$ 283)$ & $\$ 27,944(\$ 4,639)$ \\
& {$[100]$} & {$[100]$} \\
\hline
\end{tabular}

ancludes physical therapy, occupational therapy, speech therapy, chemotherapy, radiation therapy, kidney dialysis, intravenous therapy, drug or alcohol treatment, allergy shots, psychotherapy/counseling, and shots other than for allergy treatment. SE $=$ standard error.

Wald's chi-square values, ORs, and 95\% CIs of the ORs for all the variables included in the model.

The overall model was statistically significant (Wald's chisquare $=42.26$, degree of freedom $[\mathrm{df}]=20 ; P=0.001$ ). After controlling for the other variables, age, marital status, and perceived general health status were found to be statistically significantly associated with high-cost group membership. With a 1-year increase in age, patients were $6.7 \%$ less likely to be in the high-cost group (OR=0.933, 95\% CI=0.902-0.966). Patients who had a spouse or were under aged 16 years were $85.0 \%$ less likely than those without a spouse to be in the high-cost group $(\mathrm{OR}=0.150,95 \% \mathrm{CI}=0.041-0.555)$. Patients who reported having a poor self-perceived general health status were 15.6 times more likely to be in the high-cost group compared with those who reported having an excellent self-

\section{TABLE 5 Results of Logistic Regression} Procedure-Predicting HighCost Group Membership-for Dichotomized Schizophrenia-Related Direct Medical Costs by Demographic and Clinical Variables

\begin{tabular}{|c|c|c|c|c|c|c|}
\hline \multirow{2}{*}{$\begin{array}{l}\text { Demographic/ } \\
\text { Clinical Variables } \\
\text { (Reference Group) }\end{array}$} & \multirow[b]{2}{*}{ Estimate } & \multirow{2}{*}{$\begin{array}{c}\text { Wald's } \\
\text { Chi-square }\end{array}$} & \multirow{2}{*}{$\begin{array}{c}P \\
\text { Value }\end{array}$} & \multirow{2}{*}{$\begin{array}{l}\text { Odds } \\
\text { Ratio }\end{array}$} & \multicolumn{2}{|c|}{$\begin{array}{c}95 \% \text { CI of } \\
\text { Odds Ratio }\end{array}$} \\
\hline & & & & & Lower & Higher \\
\hline$\overline{\text { Age }^{a}}$ & -0.0689 & 15.5185 & $<0.001$ & 0.933 & 0.902 & 0.966 \\
\hline \multicolumn{7}{|l|}{ Sex (males) } \\
\hline Females & -0.0396 & 0.0168 & 0.897 & 0.924 & 0.279 & 3.062 \\
\hline \multicolumn{7}{|c|}{ Race (African American) } \\
\hline Caucasian & -0.6899 & 2.3280 & 0.127 & 0.430 & 0.109 & 1.689 \\
\hline Other & 0.5351 & 0.9164 & 0.338 & 1.463 & 0.250 & 8.552 \\
\hline \multicolumn{7}{|c|}{ Marital status (no spouse) } \\
\hline $\begin{array}{l}\text { Has spouse } \\
\text { or under aged } \\
16 \text { yearsa }\end{array}$ & -0.9484 & 8.0711 & 0.005 & 0.150 & 0.041 & 0.555 \\
\hline
\end{tabular}

16 years $^{\mathrm{a}}$

Insurance coverage (private insurance)

\begin{tabular}{l|r|r|r|r|r|r}
\hline Public insurance & 0.1898 & 0.2821 & 0.595 & 0.978 & 0.214 & 4.463 \\
\hline No insurance & -0.4018 & 0.4600 & 0.498 & 0.541 & 0.059 & 4.927 \\
\hline Region (Northeast) \\
\hline Midwest & 0.1481 & 0.1043 & 0.747 & 1.109 & 0.277 & 4.449 \\
\hline South & 0.6861 & 2.3809 & 0.123 & 0.482 & 0.121 & 1.923 \\
\hline
\end{tabular}

\begin{tabular}{l|l|l|l|l|l|l}
\hline West & 0.4935 & 1.5735 & 0.210 & 1.567 & 0.458 & 5.363 \\
\hline
\end{tabular}

Family income as a percentage of federal poverty level (high income)

\begin{tabular}{l|l|l|l|l|l|l}
\hline Low income & -0.2208 & 0.3193 & 0.572 & 0.643 & 0.139 & 2.975 \\
\hline
\end{tabular}

Patient-perceived general health status (excellent)

\begin{tabular}{|l|l|l|l|l|l|l}
\hline Good & -0.2743 & 0.4414 & 0.506 & 2.613 & 0.456 & 14.989 \\
\hline
\end{tabular}

\begin{tabular}{l|l|l|l|l|l|l|}
\hline Poor $^{\mathrm{a}}$ & 1.5091 & 5.0910 & 0.024 & 15.548 & 1.278 & 189.127 \\
\hline
\end{tabular}

Patient-perceived mental health status (excellent)

\begin{tabular}{l|r|r|r|r|r|r}
\hline Good & 0.1233 & 0.0640 & 0.800 & 0.543 & 0.066 & 4.439 \\
\hline Poor & -0.8577 & 0.5460 & 0.116 & 0.203 & 0.021 & 1.953 \\
\hline $\begin{array}{l}\text { Number of medi- } \\
\text { cal comorbidities }\end{array}$ & 0.1333 & 0.2271 & 0.634 & 1.143 & 0.660 & 1.977 \\
\hline $\begin{array}{l}\text { Number of mental } \\
\text { health-related } \\
\text { comorbidities }\end{array}$ & -0.3710 & 1.3095 & 0.253 & 0.690 & 0.366 & 1.303 \\
\hline
\end{tabular}

\begin{tabular}{|c|c|c|c|c|c|c|}
\hline 2006 & 3000 & 03575 & 0550 & 1000 & 023 & 5242 \\
\hline 2007 & -06767 & 14923 & 0222 & 0413 & 0075 & 2269 \\
\hline 2008 & 0.1686 & 0.1467 & 0.702 & 0.962 & 0.229 & 4.048 \\
\hline$P<0.0$ & & & & & & \\
\hline
\end{tabular}

perceived general health status (OR $=15.548,95 \% \mathrm{CI}=1.278$ 189.127). Gender, race, insurance status, region of residence, family income as a percentage of the federal poverty level, patient-perceived mental health status, and presence of medical or mental health-related comorbidities were not significantly related to high-cost group membership.

Because of the limited sample size, some of the CIs of the ORs were very wide, raising questions about the accuracy of the estimates. In addition, the cost data were positively skewed. 


\section{TABLE 6 Results of GLM Regression Procedure for Schizophrenia-Related Direct Medical Costs by Demographic and Clinical Variables}

\begin{tabular}{|c|c|c|c|c|c|c|}
\hline \multirow{2}{*}{$\begin{array}{l}\text { Demographic/ } \\
\text { Clinical Variables } \\
\text { (Reference Group) } \\
\end{array}$} & \multirow[b]{2}{*}{ Estimate } & \multirow{2}{*}{$\begin{array}{l}\text { Linearized } \\
\text { Standard } \\
\text { Errors }\end{array}$} & \multirow{2}{*}{$\begin{array}{c}\mathrm{T}- \\
\text { statistic } \\
\end{array}$} & \multirow{2}{*}{$\begin{array}{c}P \\
\text { Value }\end{array}$} & \multicolumn{2}{|c|}{$\begin{array}{c}95 \% \text { CI of } \\
\text { Point Estimate }\end{array}$} \\
\hline & & & & & Lower & Higher \\
\hline Age $^{a}$ & 0.9778 & 0.0055 & -3.93 & $<0.001$ & 0.9669 & 0.9889 \\
\hline \multicolumn{7}{|l|}{ Sex (Males) } \\
\hline Females & 0.9703 & 0.1772 & -0.17 & 0.869 & 0.6767 & 1.3913 \\
\hline \multicolumn{7}{|c|}{ Race (African American) } \\
\hline Caucasian $^{\mathrm{a}}$ & 0.5058 & 0.1258 & -2.74 & 0.007 & 0.3097 & 0.8263 \\
\hline Other & 0.6603 & 0.3061 & -0.90 & 0.372 & 0.2645 & 1.6483 \\
\hline \multicolumn{7}{|c|}{ Marital status (no spouse) } \\
\hline $\begin{array}{l}\text { Has spouse or is } \\
\text { under aged } 16 \\
\text { years }\end{array}$ & 0.6861 & 0.1587 & -1.63 & 0.105 & 0.4346 & 1.0830 \\
\hline \multicolumn{7}{|c|}{ Insurance coverage (private) } \\
\hline Public insurance & 1.2107 & 0.2953 & 0.73 & 0.434 & 0.7482 & 1.9592 \\
\hline No insurance ${ }^{a}$ & 0.4081 & 0.1637 & -2.23 & 0.027 & 0.1849 & 0.9008 \\
\hline \multicolumn{7}{|l|}{ Region (Northeast) } \\
\hline Midwest & 0.8299 & 0.2244 & -0.69 & 0.492 & 0.4867 & 1.4152 \\
\hline South $^{\mathrm{a}}$ & 0.5432 & 0.1272 & -2.61 & 0.010 & 0.3422 & 0.8624 \\
\hline West & 1.0612 & 0.2962 & 0.21 & 0.832 & 0.6118 & 1.8409 \\
\hline \multicolumn{7}{|c|}{ Family income as a percentage of federal poverty level (high income) } \\
\hline Low income & 0.7729 & 0.1544 & -1.29 & 0.199 & 0.5211 & 1.1464 \\
\hline \multicolumn{7}{|c|}{ Patient-perceived general health status (excellent) } \\
\hline Good & 0.9562 & 0.2318 & -0.18 & 0.851 & 0.5926 & 1.5430 \\
\hline Poor & 1.1529 & 0.4756 & -0.34 & 0.731 & 0.5107 & 2.0250 \\
\hline \multicolumn{7}{|c|}{ Patient-perceived mental health status (excellent) } \\
\hline Good & 1.3666 & 0.4149 & 1.03 & 0.305 & 0.7506 & 2.4880 \\
\hline Poor & 1.4862 & 0.5662 & 1.04 & 0.300 & 0.7007 & 3.1522 \\
\hline $\begin{array}{l}\text { Number of medi- } \\
\text { cal comorbidities }\end{array}$ & 1.11584 & 0.0584 & 1.72 & 0.086 & \begin{tabular}{|l|}
0.9789 \\
\end{tabular} & 1.3707 \\
\hline $\begin{array}{l}\text { Number of mental } \\
\text { health-related } \\
\text { comorbidities }\end{array}$ & 0.9140 & 0.0988 & -1.41 & 0.162 & \begin{tabular}{|l|}
0.8057 \\
\end{tabular} & 1.0370 \\
\hline \multicolumn{7}{|l|}{ Year (2005) } \\
\hline 2006 & 1.1928 & 0.3333 & 0.63 & 0.529 & \begin{tabular}{|l|}
0.6873 \\
\end{tabular} & 2.0703 \\
\hline 2007 & 0.9391 & 0.2491 & -0.24 & 0.813 & 0.5564 & 1.5850 \\
\hline 2008 & 0.9171 & 0.2410 & -0.33 & 0.742 & 0.5459 & 1.5405 \\
\hline${ }^{a} P<0.05$. & & & 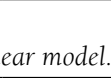 & & & \\
\hline
\end{tabular}

Therefore, a separate regression was carried out using a GLM (employing a gamma distribution with a log-link function) to evaluate the relationships between the independent variables and the schizophrenia-related direct costs as a continuous variable (Table 6). Model selection was based on the modified Park test, which gave a coefficient of 1.99, indicating a gamma distribution. Age, race, insurance coverage, and region of residence were found be statistically significantly associated with costs, while controlling for all other factors. With a 1-year increase in age, on average, the schizophrenia-related direct costs decreased by a factor of 0.98 (t-statistic $=-3.93$;
$P<0.001)$. The ratio of the schizophrenia-related direct medical costs for Caucasion patients and African American patients was 0.51 (t-statistic $=-2.74 ; P=0.007$ ); thus, Caucasion patients had lower costs than African American patients. Patients with no insurance had lower schizophrenia-related direct costs than those with private insurance, and the ratio of the mean costs for the 2 was 0.41 ( $t$-statistic $=-2.23 ; P=0.027$ ). Patients who lived in the southern United States spent less on schizophrenia-related direct costs compared with those living in the northeastern United States, and the ratio of the mean costs was 0.54 ( $t$-statistic $=-2.61 ; P=0.010$ ). Because of the difficulty in interpreting arithmetic mean ratios, we calculated the average marginal effects for each significant variable. However, it should be noted that for continuous variables, the interpretation of the average marginal effects holds only for an infinitesimal change in the independent variable. For larger changes, the values depend on the nature of the relationship between the independent and dependent variables. ${ }^{24}$ With a 1-year increase in age, the schizophrenia-related direct medical costs decreased by $\$ 125$. Caucasion patients spent $\$ 3,803$ less than African American patients on schizophrenia-related direct medical costs. Uninsured patients spent $\$ 5,001$ less than those with private insurance on schizophrenia-related costs. Schizophrenia-related expenditures for patients residing in the southern United States were $\$ 3,406$ less than those residing in the northeastern United States.

\section{Sensitivity Analysis}

Because the cutoff point for the high-cost group was relatively high, a sensitivity analysis was conducted using a lower cutoff point for the high-cost group $(\$ 5,402)$, which was also the mean cost for all patients. There were 812,703 (unweighted frequency $=90$ ) patients in the high-cost group, and 1.94 million patients (unweighted frequency $=227$ ) in the low-cost group. The bivariate analyses showed no difference with respect to any of the demographic and clinical characteristics except region of residence. A greater proportion of patients in the low-cost group, compared with the high-cost group, resided in the southern United States (42.7\% vs. $22.0 \%$ ), whereas a lower proportion of patients in the low-cost group, compared with the high-cost group, resided in the northeastern United States (19.9\% vs. 33.4\%); $(P=0.0378)$. The logistic regression procedure showed that after controlling for all other factors, patients in the South were $70.0 \%$ less likely to be in the highcost group compared with those in the Northeast $(\mathrm{OR}=0.300$, $95 \% \mathrm{CI}=0.120-0.752 ; P=0.0024)$. It was also seen that as the number of medical comorbidities increased by a single unit, patients were 1.4 times more likely to be in the high-cost group ( $\mathrm{OR}=1.384,95 \% \mathrm{CI}=1.005-1.906 ; P=0.0464)$. The tables for the bivariate and logistic regression procedures using the high-cost threshold of $\$ 5,402$ are provided in the Appendices (available online).

When $\$ 16,000$ was used as the cutoff for the high-cost 
group, the unadjusted analyses demonstrated that the highand low-cost groups differed significantly on age; when the cutoff was reduced to $\$ 5,402$, the unadjusted analyses demonstrated statistically significant difference between the 2 groups with respect to region of residence. The results obtained from the logistic regression procedures also differed; when $\$ 16,000$ was used as the cutoff for the high-cost group, age, marital status, and patient-perceived general health status were found to be significantly associated with high-cost group membership. With $\$ 5,402$ as the cutoff, region of residence and number of mental health comorbidities were found to be significant predictors of high-cost group membership.

\section{Discussion}

Based on our review of the literature, this is the first study to use a multivariate logistic regression approach to identify factors associated with high schizophrenia-related costs in the United States. The logistic regression procedure demonstrated a significant negative relationship between age and high-cost group membership. Other studies have shown negative relationships between age and schizophrenia-related costs. Dixon et al. (2001) found that younger patients were associated with greater utilization and costs associated with ambulatory care services. ${ }^{14}$ Bartels et al. (2003) found that younger patients were associated with higher expenditures for medications and outpatient services, while older patients were associated with higher nursing home costs. ${ }^{15}$ Although our study included home health care costs and inpatient costs, it did not include nursing home costs, which could explain the negative relationship found between age and costs. A similar negative relationship between age and schizophrenia-related costs was also observed by Rascati et al. (2003). ${ }^{17}$

Patients with a spouse or those under age 16 had significantly lower schizophrenia-related expenditures compared with those without a spouse. One possible explanation for this finding is the presence of family support, which may have led to more proactive medication-taking behaviors and less use of expensive services, resulting in decreased overall schizophrenia-related direct medical costs. Contrary to our expectations, married patients and those under age 16 had lower prescription medication costs $(\$ 1,301[\mathrm{SE}=\$ 306]$ vs. $\$ 2,419[\mathrm{SE}=\$ 262])$ and higher inpatient hospitalization costs $(\$ 1,587$ [SE $=803$ ] vs. $\$ 780$ [SE $=278]$ ) compared with the unmarried patients. However, the married patients and patients under age 16 had lower costs for other expensive services, such as home health care visits $(\$ 121[\mathrm{SE}=\$ 101])$ vs. $\$ 799[\mathrm{SE}=\$ 348])$ and office-based physician visits $(\$ 1,237[\mathrm{SE}=\$ 564]$ vs. $\$ 1,433[\mathrm{SE}=\$ 249])$. Previous research has shown that patients with poor perceived general health status are more likely to utilize health care services, which translates into higher health care costs. ${ }^{25}$

Because the limited sample size within each cost category may have led to unstable OR estimates, a GLM regression using a gamma distribution and log-link function was carried out. The GLM regression procedure showed that age, race, insurance status, and region of residence were significantly associated with schizophrenia-related direct costs. A negative association between age and schizophrenia-related direct costs was observed in the study by Bartels et al. ${ }^{15}$ A similar association was also observed in the logistic and linear regression analyses of the current study. Dixon et al. ${ }^{14}$ observed that Caucasians had higher expenditures as compared with African Americans; however, the opposite was observed in this study. One potential explanation is higher utilization of more expensive services (e.g., inpatient hospitalizations, home health care) among African Americans. The lower costs among the uninsured is probably due to lower utilization of routine services because of lack of insurance, since expenditures such as prescription medications and physician office visits make up a large proportion of the schizophrenia-related direct costs for community-dwellers. Although we had more schizophrenia patients in the southern states as compared with the northeastern states (contrary to that reported by Torrey and Bowler [1990]), the higher costs in the Northeast are likely due to more expensive health care services in this region. ${ }^{26}$

Neither the bivariate analysis nor the regression analysis showed a significant relationship between the number of comorbidities and costs. However, the nature of the relationship was reversed for the 2 analyses. The unadjusted analysis (t-test) showed that patients in the high-cost group had fewer comorbidities than those in the low-cost group, whereas the regression analyses showed that, after controlling for other factors, the number of medical comorbidities was positively associated with costs. The small sample size likely played a role in the lack of statistical significance. The number of mental health-related comorbidities was lower for the high-cost group in both the unadjusted and adjusted analyses. This trend was also observed by Rascati et al. in which patients with a history of mental illnesses were associated with lower schizophreniarelated costs. ${ }^{17}$

The results of the sensitivity analyses demonstrate that the statistical significance associated with the predictors was sensitive to the definition used for the high-cost group. Logistic regression using $\$ 16,000$ as the cutoff point showed that age, marital status, and patient-perceived general health status were significant predictors of high-cost group membership; when $\$ 5,402$ was used as the cutoff, region of residence and number of medical comorbidities were significant predictors. Thus, the logistic regression results vary depending on the choice of high-cost cutoff points, a situation that is avoided in the GLM.

Identifying the characteristics of the high-risk population may help health care providers at the grass roots level to be mindful of patients most likely to have high expenditures. Demographic characteristics are easily identifiable. Plan coordinators can assign case managers to these patients early on during the course of their disease, and health care providers could encourage these patients to have regular physician visits 
and to carefully follow their medication treatment regimens. Improving continuity of antipsychotic medications and having regular physician visits could help control costs by preventing expensive services such as inpatient hospitalizations. ${ }^{27,28}$ At the health plan level, consideration of the effects of formulary coverage decisions, formulary tier placement, and prior authorization requirements on high-cost patients may be helpful in achieving desired outcomes. High-cost patients could also be potential candidates for medication therapy management services by pharmacists, which could encourage them to improve medication management and adherence and could potentially lead to lower health care costs. ${ }^{29}$

\section{Limitations}

There are some limitations to this study that affect interpretation of the results. Due to the low prevalence of schizophrenia, 4 years of MEPS data were pooled to obtain a sufficiently large sample size to yield reliable estimates. The samples from consecutive years may not be completely independent because the samples are drawn from the same geographic region, and several patients may be in the sample for 2 consecutive years. Therefore, some of the observations for the regression procedures, which were carried out on a sample of all the patients with schizophrenia between 2005 and 2008, are not independent. However, if the costs for the same patient from consecutive years were added, then costs from 2 years would be counted for patients with schizophrenia from 2006 and 2007, while costs from only 1 year would be counted for patients from 2005 and 2008 (the first and last year included in the analyses), which would lead to inaccurate per-person and per-year estimates. In order to avoid this inconsistency, we chose to treat the patients in each year as independent observations. According to MEPS documentation, it is valid to keep all observations and treat them as independent, since each year's data are designed to be nationally representative. ${ }^{30}$ In order to ensure that accurate standard errors are obtained, the survey procedure of SAS and the "svy" procedure of Stata were used for the analysis, as it accounts for the complex sampling design of MEPS.

Despite combining 4 years of MEPS data to ensure a sufficiently large sample size, some of the categories for the independent variables in the logistic regression procedure had a smaller than desired sample size. This may affect the reliability of those estimates. However, studies have been conducted in the past using MEPS for the same disease state.

Since the household component of MEPS consists of noninstitutionalized community-dwelling residents, schizophrenia patients living in supported living facilities, nursing homes, institutions, and prisons were not included. Homeless people and undocumented immigrants were also not included, and they are likely to incur high costs. Thus, the studied population is not representative of all schizophrenia patients in the
United States. The subjects for the current study consist of community-dwelling schizophrenia patients who are likely to be higher functioning and less severely ill.

Patients were identified using ICD-9-CM codes only. Because of the stigma associated with the disease, physicians are known to give interim nonschizophrenia diagnoses, when uncertain, until schizophrenia can be confirmed. In addition, the conditions in MEPS are self-reported by the patients. This could lead to under-representation of schizophrenia patients.

Only schizophrenia-related direct medical costs were included in this study. Costs associated with comorbidities potentially related to schizophrenia were excluded because of the difficulties in establishing a causal relationship between schizophrenia and those comorbidities in a cross-sectional dataset such as MEPS.

\section{Conclusion}

This is the first study that attempted to identify the characteristics of schizophrenia patients associated with high schizophrenia-related direct costs in the noninstitutionalized U.S. population. A number of demographic and clinical factors were included in the analysis. The characteristics associated with high-cost group membership were identified using logistic regression. In addition, a GLM regression was carried out to determine the association between the demographic and clinical factors and direct costs related to schizophrenia. A modified Park test was used to determine the appropriate distribution for the model prior to conducting the GLM regression.

In recent years, policymakers and researchers have been trying to find ways to improve the delivery of health care while controlling increases in health care costs, especially for the subset of patients who are responsible for a disproportionately large share of overall health care expenditures. ${ }^{31}$ This study helps identify community-dwelling schizophrenia patients who are responsible for a disproportionately high level of schizophrenia-related health care expenditures. Identifying the high-cost population may help policymakers allocate resources more efficiently and health care providers manage patients more effectively through assignment of high-risk patients to case managers and appropriate monitoring and treatment.

\section{Authors}

POOJA DESAI, MS, is a Doctoral Candidate; KENNETH A. LAWSON, PhD, is Professor and Division Head; Jamie C. Barner, $P h D$, is Professor; and Karen L. Rascati, PhD, is Professor, The University of Texas at Austin College of Pharmacy, Austin, Texas.

AUTHOR CORRESPONDENCE: Kenneth A. Lawson, PhD, The University of Texas at Austin College of Pharmacy, 2409 University Ave., Stop A1930, Austin, TX 78712. Tel.: 512.471.5609;

Fax: 512.471.8762; E-mail: ken.lawson@austin.utexas.edu. 


\section{DISCLOSURES}

No funding was received for this study. The authors report no conflict of interest regarding this study.

Study concept and design were contributed equally by Desai, Lawson, Barner, and Rascati. Desai had primary responsibility for data collection with assistance from Lawson, Barner, and Rascati. All authors shared equally in data interpretation. The manuscript was written and revised primarily by Desai and Lawson with assistance from Barner and Rascati.

\section{REFERENCES}

1. Reus VI. Mental disorders. In: Fauci AS, Braunwald E, Kasper D, et al., eds. Harrison's Principles of Internal Medicine. 17th ed. New York: McGraw Hill Companies, Inc.; 2008.

2. Kessler RC, Birnbaum H, Demler O, et al. The prevalence and correlates of nonaffective psychosis in the National Comorbidity Survey Replication (NCS-R). Biol Psychiatry. 2005;15(8):668-76.

3. Robins LN, Regier DA, eds. Psychiatric Disorders in America: The Epidemiologic Catchment Area Study. New York: The Free Press; 1990.

4. Gunderson JG, Mosher LR. The cost of schizophrenia. Am J Psychiatry. 1975;132(9):901-06.

5. Rice DP, Miller LS. The economic burden of schizophrenia: conceptual and methodological issues, and cost estimates. In: Moscarelli M, Rupp A, Sartorius N, eds. Handbook of Mental Health Economics and Health Policy. Vol. 1, Schizophrenia. New York: John Wiley; 1996.

6. Rice DP. The economic impact of schizophrenia. J Clin Psychiatry. 1999;60(Suppl 1):4-6.

7. Wyatt RJ, Henter I, Leary MC, Taylor E. An economic evaluation of schizophrenia-1991. Soc Psychiatry Psychiatr Epidemiol. 1995;30(5):196-205.

8. Wu EQ, Birnbaum HG, Shi L, et al. The economic burden of schizophrenia in the United States in 2002. J Clin Psychiatry. 2005;66(9):1122-29.

9. McDonald M, Hertz RP, Lustik MB, Unger AN. Healthcare spending for community-dwelling adults with schizophrenia. Am J Manag Care. 2005;11 (8 Suppl):S242-S247.

10. Conwell LJ, Cohen JW. Characteristics of persons with high medical expenditures in the U.S. civilian noninstitutionalized population, 2002. MEPS Statistical Brief \#73. March 2005. Agency for Healthcare Research and Quality, Rockville, MD. Available at: http://meps.ahrq.gov/data_files/publications/st73/stat73.pdf. Accessed April 11, 2013.

11. Terkelsen KG, Menikoff A. Measuring the costs of schizophrenia. Implications for a post-institutional era in the U.S. Pharmacoeconomics. 1995;8(3):199-222.

12. Andersen RM. Revisiting the behavioral model and access to medical care: does it matter? J Health Soc Behav. 1995;36(1):1-10.

13. Lin H-C, Erickson SR, Balkrishnan R. Antidepressant utilization, adherence, and health care spending in the United States: the case of MDD patients 2000-2007. Health Outcomes Res Med. 2011;2(2):e79-89 Available at: http://www.sciencedirect.com/science/article/pii/S1877131911000152. Accessed April 11, 2013.

14. Dixon L, Lyles A, Smith C, et al. Use and costs of ambulatory care services among Medicare enrollees with schizophrenia. Psychiatr Serv. 2001;52(6):786-92.
15. Bartels SJ, Clark RE, Peacock WJ, Dums AR, Pratt SI. Medicare and Medicaid costs for schizophrenia patients by age cohort compared with costs for depression, dementia, and medically ill patients. Am J Geriatr Psychiatry. 2003;11(6):648-57.

16. Crown WH, Neslusan C, Russo PA, Holzer S, Ozminkowski R, Croghan T. Hospitalization and total medical costs for privately insured persons with schizophrenia. Adm Policy Ment Health. 2001;28(5):335-51.

17. Rascati KL, Johnsrud MT, Crismon ML, Lage MJ, Barber BL. Olanzapine versus risperidone in the treatment of schizophrenia: a comparison of costs among Texas Medicaid recipients. Pharmacoeconomics. 2003;21(10):683-97.

18. Wu EQ, Shi L, Birnbaum H, Hudson T, Kessler R. Annual prevalence of diagnosed schizophrenia in the USA: a claims data analysis approach. Psychol Med. 2006;36(11):1535-40.

19. Cohen CI, Cohen GD, Blank K, et al. Schizophrenia and older adults. An overview: directions for research policy. Am J Geriatr Psychiatry. 2000;8(1):19-28.

20. Agency for Healthcare Research and Quality (AHRQ). Medical Expenditure Survey Panel (MEPS): survey background. Last revised August 21, 2009. Available at: http://www.meps.ahrq.gov/mepsweb/about_meps/ survey_back.jsp. Accessed April 11, 2013.

21. MEPS-HC Sample design and collection process. Agency for Healthcare Research and Quality, Rockville, MD. Available at: http://www.meps.ahrq. gov/survey_comp/hc_data_collection.jsp. Accessed April 11, 2013.

22. Manning WG, Mullahy J. Estimating log models: to transform or not to transform? J Health Econ. 2001;20(4):461-94.

23. Glick HA, Doshi JA, Sonnad SS, Polsky D, eds. Economic Evaluation in Clinical Trials. Oxford: Oxford University Press; 2007.

24. Williams R. Marginal effects \& discrete change. Margins Part 2 Available at: http://www3.nd.edu/ rwilliam/stats3/Margins02.pdf. Accessed May 24, 2013

25. Berra S, Borrell C, Rajmil L, et al. Perceived health status and use of healthcare services among children and adolescents. Eur J Public Health. 2006;16(4):405-14.

26. Torrey EF, Bowler A. Geographic distribution of insanity in America: evidence for an urban factor. Schizophr Bull. 1990;16(4):591-604.

27. Marcus SC, Olfson M. Outpatient antipsychotic treatment and inpatient costs of schizophrenia. Schizophr Bull. 2008;34(1):173-80.

28. Zeidler J, Slawik L, Fleischmann J, Greiner W. The costs of schizophrenia and predictors of hospitalization from the statutory health insurance perspective. Health Econ Rev. 2012;2(1):9.

29. Branham A, Moose J, Ferreri S. Retrospective analysis of medication adherence and cost following medication therapy management. Inov Pharm. 2010;1(1):8. Available at: http://www.pharmacy.umn.edu/innovations/prod/ groups/cop/@pub/@cop/@innov/documents/article/cop_article_254656.pdf. Accessed April 11, 2013.

30. Medical Expenditure Panel Survey. MEPS HC-036: 1996-2008 Pooled estimation file. Agency for Healthcare Research and Quality, Rockville, MD. Available at: http://www.meps.ahrq.gov/mepsweb/data_stats/download_ data/pufs/h36/h36u08doc.shtml\#30Survey. Accessed April 11, 2013.

31. Jacobson G, Neuman T, Damico A. Medicare spending and use of medical services for beneficiaries in nursing homes and other long-term care facilities: a potential for achieving Medicare savings and improving the quality of care. The Henry J. Kaiser Family Foundation. October 2010. Available at: http://www.kff.org/medicare/upload/8109.pdf. Accessed April 11, 2013. 


\section{Identifying Patient Characteristics Associated with High Schizophrenia-Related Direct Medical Costs in Community-Dwelling Patients}

APPENDIX A Chi-square Analysis of Demographic and Clinical Characteristics by High- and Low-Cost Groups Using $\$ 5,402$ as Cutoff for High-Cost Group

\begin{tabular}{|c|c|c|c|c|c|c|c|}
\hline \multirow{2}{*}{$\begin{array}{l}\text { Demographic/Clinical } \\
\text { Variables }\end{array}$} & \multirow[b]{2}{*}{ Categories } & \multicolumn{2}{|c|}{ Low-Cost Group } & \multicolumn{2}{|c|}{ High-Cost Group } & \multirow{2}{*}{$\begin{array}{c}\text { Rao-Scott } \\
\text { Chi-square } \\
\text { Statistic }\end{array}$} & \multirow[b]{2}{*}{$P$ Value } \\
\hline & & Weighted N & Percentage & Weighted N & Percentage & & \\
\hline \multirow[t]{2}{*}{ Gender } & Male & $1,042,507$ & 53.8 & 484,722 & 59.6 & 0.5079 & 0.4760 \\
\hline & Female & 895,227 & 46.2 & 327,981 & 40.4 & & \\
\hline \multirow[t]{3}{*}{ Race } & African American & 409,192 & 21.1 & 267,240 & 32.9 & 4.8091 & 0.0903 \\
\hline & Caucasian & $1,446,335$ & 74.6 & 497,694 & 61.2 & & \\
\hline & Other $^{\mathrm{a}}$ & 82,208 & 4.2 & 47,769 & 5.9 & & \\
\hline \multirow[t]{2}{*}{ Marital status } & $\begin{array}{l}\text { Has spouse or is less than } \\
16 \text { years of age }\end{array}$ & 373,645 & 19.3 & 81,643 & 10.0 & 2.2850 & 0.1306 \\
\hline & No spouse ${ }^{c}$ & $1,564,089$ & 80.7 & 731,060 & 90.0 & & \\
\hline \multirow[t]{3}{*}{ Insurance coverage } & Private insurance & 394,824 & 20.4 & 158,876 & 19.5 & 0.0823 & 0.9597 \\
\hline & Public insurance & $1,406,279$ & 72.6 & 604,577 & 74.4 & & \\
\hline & No insurance & 136,631 & 7.1 & 49,250 & 6.1 & & \\
\hline \multirow[t]{4}{*}{ Region } & Northeast & 385,206 & 19.9 & 271,606 & 33.4 & 8.4384 & 0.0378 \\
\hline & Midwest & 370,215 & 19.1 & 195,014 & 24.0 & & \\
\hline & South & 828,071 & 42.7 & 178,837 & 22.0 & & \\
\hline & West & 354,243 & 18.3 & 167,246 & 20.6 & & \\
\hline \multirow{2}{*}{$\begin{array}{l}\text { Family income as a percentage } \\
\text { of federal poverty level }\end{array}$} & Low incomed & $1,251,748$ & 64.6 & 515,919 & 63.5 & 0.0196 & 0.8887 \\
\hline & High income $e^{\mathrm{e}}$ & 685,986 & 35.4 & 296,785 & 36.5 & & \\
\hline \multirow{3}{*}{$\begin{array}{l}\text { Patient-perceived general } \\
\text { health status }\end{array}$} & Excellent $^{\mathrm{f}}$ & 472,934 & 24.4 & 223,593 & 27.5 & 0.2401 & 0.8869 \\
\hline & Goodg & $1,271,973$ & 65.6 & 517,424 & 63.7 & & \\
\hline & Poor & 192,827 & 10.0 & 71,685 & 8.8 & & \\
\hline \multirow{3}{*}{$\begin{array}{l}\text { Patient-perceived mental } \\
\text { health status }\end{array}$} & Excellent $^{\mathrm{f}}$ & 265,770 & 9.0 & 101,162 & 12.4 & 0.2930 & 0.8637 \\
\hline & Goodg & $1,337,476$ & 45.5 & 549,031 & 67.6 & & \\
\hline & Poor & 334,489 & 11.4 & 162,510 & 20.0 & & \\
\hline \multirow[t]{4}{*}{ Year } & 2005 & 468,809 & 24.2 & 206,015 & 25.3 & 0.1634 & 0.9833 \\
\hline & 2006 & 374,615 & 19.3 & 164,020 & 20.2 & & \\
\hline & 2007 & 568,238 & 29.3 & 216,281 & 26.6 & & \\
\hline & 2008 & 526,073 & 27.1 & 226,387 & 27.9 & & \\
\hline \multicolumn{8}{|c|}{ "American Indian/Alaskan Native, Asian, Native Hawaiian/Pacific Islander, and multiple races reported collapsed into "Other." } \\
\hline
\end{tabular}

APPENDIX B T-test Analysis of Demographic and Clinical Characteristics by High- and Low-Cost Groups Using $\$ 5,402$ as Cutoff for High-Cost Group

\begin{tabular}{|c|c|c|c|c|c|c|}
\hline \multirow[b]{2}{*}{ Demographic/Clinical Variables } & \multicolumn{2}{|c|}{ Low-Cost Group } & \multicolumn{2}{|c|}{ High-Cost Group } & \multirow[b]{2}{*}{ T-statistic } & \multirow[b]{2}{*}{$P$ Value } \\
\hline & Mean & SE & Mean & SE & & \\
\hline Age & 44.0 & 1.6 & 40.7 & 2.1 & -1.44 & 0.1520 \\
\hline Number of clinical comorbidities & 0.81 & 0.09 & 1.01 & 0.14 & 1.22 & 0.2235 \\
\hline Number of mental health-related comorbidities & 1.22 & 0.13 & 1.04 & 0.20 & -0.79 & 0.4306 \\
\hline
\end{tabular}


APPENDIX C Results of Logistic Regression Procedure: Predicting High-Cost Group Membership for Dichotomized Schizophrenia-Related Direct Medical Costs by Demographic and Clinical Variables Using \$5,402 as Cutoff for High-Cost Group

\begin{tabular}{|c|c|c|c|c|c|c|}
\hline \multirow[b]{2}{*}{ Demographic/Clinical Variables（Reference Group） } & \multirow[b]{2}{*}{ Estimate } & \multirow{2}{*}{$\begin{array}{c}\text { Wald's } \\
\text { Chi-square }\end{array}$} & \multirow[b]{2}{*}{$P$ Value } & \multirow[b]{2}{*}{ Odds Ratio } & \multicolumn{2}{|c|}{$95 \%$ CI of Odds Ratio } \\
\hline & & & & & Lower & Higher \\
\hline Age & -0.0216 & 3.6398 & 0.0564 & 0.979 & 0.957 & 1.001 \\
\hline \multicolumn{7}{|l|}{ Sex (Males) } \\
\hline Females & -0.0594 & 0.1980 & 0.0900 & 0.888 & 0.409 & 1.930 \\
\hline \multicolumn{7}{|l|}{ Race (African American) } \\
\hline Caucasian & -0.4345 & 3.3450 & 0.0674 & 0.414 & 0.155 & 1.106 \\
\hline Other & -0.0123 & 0.0010 & 0.9753 & 0.632 & 0.146 & 2.728 \\
\hline \multicolumn{7}{|l|}{ Marital status (no spouse) } \\
\hline Has spouse or is under aged 16 years & -0.4196 & 2.3807 & 0.1228 & 0.432 & 0.149 & 1.255 \\
\hline \multicolumn{7}{|l|}{ Insurance coverage (private insurance) } \\
\hline Public insurance & 0.0744 & 0.0698 & 0.7916 & 0.801 & 0.338 & 1.897 \\
\hline No insurance & -0.3704 & 0.6084 & 0.4354 & 0.513 & 0.108 & 2.440 \\
\hline \multicolumn{7}{|l|}{ Region (Northeast) } \\
\hline Midwest & 0.1650 & 0.3251 & 0.5686 & 0.837 & 0.328 & 2.131 \\
\hline Southa & -0.8598 & 9.2132 & 0.0024 & 0.300 & 0.120 & 0.752 \\
\hline West & 0.3513 & 1.1974 & 0.2738 & 1.008 & 0.383 & 2.652 \\
\hline \multicolumn{7}{|c|}{ Family income as a percentage of federal poverty level (high income) } \\
\hline Low income & 0.0907 & 0.1813 & 0.6703 & 1.199 & 0.520 & 2.762 \\
\hline \multicolumn{7}{|l|}{ Patient-perceived general health status (excellent) } \\
\hline Good & -0.1081 & 0.1729 & 0.6775 & 0.730 & 0.343 & 1.555 \\
\hline Poor & -0.0983 & 0.0493 & 0.8243 & 0.737 & 0.176 & 3.088 \\
\hline \multicolumn{7}{|l|}{ Patient-perceived mental health status (excellent) } \\
\hline Good & 0.0886 & 0.1444 & 0.7040 & 1.420 & 0.550 & 3.663 \\
\hline Poor & 0.1733 & 0.3355 & 0.5625 & 1.545 & 0.493 & 4.840 \\
\hline Number of medical comorbidities ${ }^{a}$ & 0.3252 & 3.9667 & 0.0464 & 1.384 & 1.005 & 1.906 \\
\hline Number of mental health-related comorbidities & -0.1372 & 0.8232 & 0.3642 & 0.872 & 0.648 & 1.173 \\
\hline \multicolumn{7}{|l|}{ Year (2005) } \\
\hline 2006 & 0.1255 & 0.2283 & 0.6328 & 1.054 & 0.394 & 2.822 \\
\hline 2007 & -0.1150 & 0.2178 & 0.6407 & 0.829 & 0.320 & 2.148 \\
\hline 2008 & -0.0833 & 0.2892 & 0.7734 & 0.855 & 0.325 & 2.253 \\
\hline
\end{tabular}

